\title{
Correction to: The Small Punch Test a Viable Alternate for In- service Components Preserved Strength Estimation
}

\author{
Pruthvish Patel $^{1}$ (D) B. K. Patel $^{2}$
}

Published online: 30 August 2021

(C) The Institution of Engineers (India) 2021

Correction to: J. Inst. Eng. India Ser. C https://doi.org/10.1007/s40032-021-00728-1

Unfortunately, the article was published with some errors in the online publication.

The corrections are as follows:

The Heading "Summary" in the article should read as "conclusion" in the article.

The first line, in the third paragraph of conclusion should read as,

"As it has been realized the scattered results for ductile iron, 65-45-12 material strength characterization using the published factors and characterization methods, prompts the great scope of improvement for the SP testing methodology and guideline to post-process the results for accurate mechanical characterization for the universal class of materials".

Publisher's Note Springer Nature remains neutral with regard to jurisdictional claims in published maps and institutional affiliations.

The original article can be found online at https://doi.org/10.1007/ s40032-021-00728-1.

Pruthvish Patel

prithvish.patel@gmail.com

1 Gujarat Technological University, Ahmedabad, Gujarat, India

2 Mechanical Engineering Department, L. D. College of Engineering, Ahmedabad, Gujarat, India 